\title{
Kolam Retensi Sebagai Upaya Pengendalian Banjir Pada Daerah Aliran Sungai Batang Pangian
}

\author{
Syofyan. Z \\ Dosen Jurusan Teknik Sipil, Fakultas Teknik Sipil dan Perencanaan \\ Institut Teknologi Padang ${ }^{1}$ \\ DOI: http://dx.doi.org/10.31869/rtj.v5i1.2856
}

\begin{abstract}
Abstrak: Banjir adalah bencana alam yang terjadi ketika air menggenangi daratan.Banjir biasanya disebabkan oleh air yang tidak dapat mengalir melalui saluran pembuangan yang tersumbat karena sampah. Drainase kota yang tidak mampu mengalirkan air dan luapan sungai menyebabkan genangan banjir di daerah perkotaan. Adapun beberapa faktor penyebab terjadinya banjir yaitu faktor topografi, intensitas hujan yang tinggi, penyumbatan saluran air, kurangnya daerah resapan air dan sebagainya.Banjir akibat luapan sungai terjadi hampir setiap tahun di Kabupaten Dharmasraya.Daerah Aliran Sungai Batang Pangian merupakan salah satu wilayah yang terdampak banjir setiap tahun.Hasil analisa arah aliran dan matriks D8 di wilayah tersebut menunjukkan genangan banjir di daerah pemukiman.

Kolam retensi merupakan upaya konservasi dalam mengatasi masalah banjir di daerah perkotaan.Kolam retensi berfungsi untuk menampung sementara volume banjir yang berpotensi menggenangi pemukiman.Dengan adanya perencanaan kolam retensi diharapkan resiko yang diakibatkan oleh banjir dapat berkurang. Dengan melakukan pengolahan data curah hujan selama 10 tahun terakhir menggunakan Metode Log Person III, untuk selanjutnya dilakukan perhitungan debit banjir rencana dengan menggunakan Metode Hidrograf Satuan Sintetik Nakayasu.

Untuk debit maksimum adalah 200,69 $\mathrm{m}^{3} / \mathrm{s}$ dengan memakai periode ulang 25 tahun berdasarkan jenis bangunan pada sungai. Waktu konsentrasi yang dibutuhkan untuk mencapai debit puncak yaitu selama 128,40 menit. Perencanaan kolam retensi menggunakan model ArcSWAT yang merupakan interface dari aplikasi ArcGIS. Untuk efektivitas penggunaan kolam retensi diatas 75\%, dibutuhkan volume kolam retensi minimal sebesar $35.620 \mathrm{~m}^{3}$. Umtuk mendapatkan volume efektif yang dapat ditampung kolam retensi, maka debit yang akan ditampung adalah debit limpasan sungai. Debit limpasan didapat dengan mengurangi debit banjir rencana dengan debit aliran sungai. Debit aliran sungai dapat dihitung dengan menggunakan rumus Manning. Kolam retensi dapat mencapai volume maksimum dalam waktu 98,14 menit atau 1,63 jam.
\end{abstract}

Kata kunci : Banjir, Batang Pangian, Hidrologi, Dharmasraya, Kolam Retensi.

\section{PENDAHULUAN}

Banjir merupakan suatu bencana alam yang terjadi ketika daratan digenangi air secara berlebihan.Banjir biasanya terjadi disebabkan oleh banyak faktor, baik itu berupa faktor alam maupun faktor manusia.Adapun beberapa faktor penyebab terjadinya banjir yaitu faktor topografi, intensitas hujan yang tinggi, penyumbatan saluran air, kurangnya daerah resapan air dan sebagainya.Banjir sering terjadi di wilayah pedesaan maupun perkotaan.

Sumatera Barat merupakan salah satu provinsi dengan curah hujan yang cukup tinggi, sehingga hampir setiap daerah di Sumatera Barat memiliki potensi untuk terjadinya banjir.Kabupaten Dharmasraya merupakan salah satu daerah yang memiliki potensi untuk terjadinya banjir.Terjadinya banjir diakibatkan oleh tingginya curah hujan dengan durasi yang cukup lama, sehingga air sungai meluap ke pemukiman warga dan mengganggu aktifitas warga.

Banjir yang terjadi juga disebabkan kurangnya daerah resapan air di sekitar sungai, sehingga apabila terjadi hujan dengan intensitas yang tinggi dan dengan durasi yang cukup lama akan menyebabkan genangan air yang lama-kelamaan juga akan menggenangi daerah pemukiman di sekitar sungai.

Pemukiman warga, area pertanian, area perkebunan, dan bangunan infrasruktur seperti jalan dan jembatan adalah yang paling terkena dampak oleh terjadinya banjir. Banjir juga mengakibatkan kerugian sosial dan ekonomi, karena jalannya kegiatan perekonomian warga dan proses pendidikan akan terganggu apabila terjadi banjir.

Nagari Gunung Selasih, Kecamatan Pulau Punjung, Kabupaten Dharmasraya merupakan daerah yang terdampak banjir dan merupakan 
bagian dari DAS Batang Pangian. Ketinggian air yang mencapai 1 meter ini mengakibatkan banyak rumah warga yang terendam banjir (https://hariansinggalang.co.id/banjir-didharmasraya-sejumlah-jorong-terisolasi/2018).

Sistem darinase perkotaan yang berkelanjutan dan ramah lingkungan merupakan salah satu upaya pengendalian banjir pada daerah pemukiman yang disebabkan oleh air hujan. Pembangunan Kolam Retensi merupakan salah satu sistem drainase yang berguna sebagai upaya untuk pengendalian banjir. Kolam Retensi dapat menampung air limpasan permukaan (runoff) atau menampung air dari drainase yang selanjutnya akan diresapkan ke dalam tanah. Penempatan Kolam Retensi yang benar akan memberikan dampak yang lebih efektif terhadap upaya pengendalian banjir.

Penelitian ini akan mencoba mengidentifikasi lokasi yang terdampak genangan banjir akibat hujan dan genangan sungai di Daerah Aliran Sungai Batang Pangian yang berada di Kabupaten Dharmasraya dengan menggunakan Sistem Informasi Geografis (SIG) dan melakukan perhitungan hidrologi untuk perencanaan Kolam Retensi. Berdasarkan pengolahan datadata tersebut, maka penulis akan mengangkat judul penelitian ini yaitu "Kolam Retensi Sebagai Upaya Pengendalian Banjir pada Daerah Aliran Sungai Batang Pangian”.

\section{TINJAUAN PUSTAKA \\ Banjir}

Banjir adalah bencana alam yang terjadi karena luapan sungai, waduk, dan lain-lain yang daerahnya tidak mampu meresap air dan menggenangi dataran yang lebih rendah.Banjir juga disebabkan oleh curah hujan yang tinggi dan gelombang pasang yang membanjiri dataran yang lebih rendah (Somantri, 2008).

Banjir adalah suatu keadaan sungai dimana aliran airnya tidak tertampung oleh saluran pembuang (palung sungai) atau terhambatnya aliran air di dalam saluran pembuang sehingga meluap menggenangi daerah sekitarnya (Suripin, 2004). Hal ini dikarenakan debit banjir yang lebih besar dari kapasitas sungai yang ada. Banjir adalah perluapan atau genangan yang berasal dari sungai, hujan atau kumpulan air lainnya yang menyebabkan kerusakan (Hendi Haryadi, 2006). Sedangkan menurut Arief Rosyidie
(2013), banjir dapat terjadi karena debit atau volume air yang mengalir pada suatu sungai atau saluran drainase melebihi atau diatas kapasitas pengalirannya.

Menurut Gultom (2012), kategori atau jenis banjir terbagi berdasarkan lokasi aliran sumber permukaannya dan berdasarkan mekanisme terjadinya banjir yaitu :

1. Berdasarkan lokasi sumber aliran permukaannya terdiri dari :

a) Banjir kiriman (banjir bandang) yaitu banjir yang diakibatkan oleh tingginya curah hujan di daerah hulu sungai.

b) Banjir lokal yaitu banjir yang terjadi karena volume hujan setempat yang melebihi kapasitas pembuangan di suatu wilayah.

2. Berdasarkan mekanisme terjadinya banjir :

a) Regular Fload yaitu banjir yang diakibatkan oleh hujan.

b) Irregular Fload yaitu banjir yang diakibatkan oleh selain hujan seperti tsunami, gelombang pasang, dan hancurnya bendungan.

Banjir disebabkan oleh banyak faktor, namun secara umum penyebab terjadinya banjir diklasifikasikan menjadi dua kategori, yaitu banjir yang disebabkan oleh faktor alami dan banjir yang disebabkan oleh tindakan manusia (Sugiyanto, 2002). Adapun penyebab banjir dari faktor alami yaitu :

1. Pengaruh Fisiografi

Fisiografi adalah segala sesuatu yang berhubungan dengan kondisi fisik atau bentuk fisik sungai, bentuk dan arah aliran, kemiringan daerah aliran sungai, lokasi sungai, dan bentuk penampang sungai.Fisiografi dari sungai sangatlah berpengaruh terhadap terjadinya banjir.

2. Curah Hujan

Curah hujan yang tinggi di suatu daerah pada waktu yang lama akan mempengaruhi potensi terjadinya banjir pada wilayah tersebut.

3. Pendangkalan Sungai

Pendangkalan sungai biasanya disebabkan oleh sedimentasi.Sedimen ini dibawa dari hulu ke hilir sungai berupa batu atau pasir yang mengakibatkan pendangkalan sungai.Pendangkalan sungai mengakibatkan berkurangnya volume aliran sungai.

4. Pasang Air Laut

Pasang air laut berakibat berkurangnya kecepatan aliran dari sungai ke laut. Pada saat terjadinya hujan dan pasang secara bersamaan, 
hal ini akan menyebabkan backwater yang akan menyebabkan banjir.

Sedangakan penyebab terjadinya banjir oleh faktor manusia yaitu :

1. Penebangan Hutan

Penebangan hutan yang dilakukan secara terus menerus dan dalam skala besar tanpa adanya tindak penghijauan kembali akan mengakibatkan menurunnya kemampuan tanah dalam meresap air.

2. Kawasan Kumuh

Perumahan yang dibangun di bantaran sungai akan menghambat aliran sungai, dampak lainnya adalah badan sungai yang semakin kecil karena adanya perumahan tersebut.

3. Perubahan Tata Guna Lahan

Banyak lahan hijau yang berubah fungsi menjadi perumahan, perkantoran, jalan raya dan lain sebagainya, jika perubahan tata guna lahan ini tidak diatur dan dikelola secara baik akan menimbulkan permasalahan banjir.

4. Pembuangan Sampah Sembarangan

Kebiasaan buruk yang sering dilakukan oleh masyarakat yaitu membuang sampah sembarangan. Sampah tersebut jika masuk ke sungai akan menyebabkan tersumbatnya aliran sungai dan akan menyebabkan banjir.

Untuk mengurangi dampak bencana banjir yang terjadi pada daerah aliran sungai, maka perlu penanganan yang dilakukan secara utuh mulai dari hulu sampai hilir (Presiden Republik Indonesia, 2012).

\section{Pengendalian Banjir}

Pengendali Banjir adalah bangunan untuk mengendalikan tinggi muka air agar tidak terjadi limpasan atau genangan yang menimbulkan kerugian (Direktorat Jenderal Cipta Karya, 2010).Pengendalian banjir merupakan suatu kegiatan dimulai dari perencanaan, pelaksanaan pekerjaan dan pemeliharaan yang bertujuan untuk mengendalikan banjir, mengurangi atau mencegah bahaya, dan kerugian akibat banjir.Menurut Grigg (1996) dalam Arief Rosyadie (2013), upaya untuk mencegah dampak banjir dapat dilakukan secara struktural dan non struktural. Berikut merupakan upaya-upaya yang dapat dilakukan secara struktural dan non struktural :

1. Upaya secara struktural dapat berupa perbaikan dan pengaturan sistem sungai (normalisasi sungai, sudeten, perlindungan tanggul, dan lain-lain) dan bangunan pengendali banjir (bendungan/dam, kolam retensi, pembuatan checkdam, dan lain-lain).

2. Upaya secara non struktural yang merupakan upaya penyesuaian dan pengaturan kegiatan manusia supaya harmonis dan serasi dengan lingkungan seperti pengaturan maupun pengendalian penggunaan lahan atau tata ruang, penegakan peraturan atau hukum, pengawasan, penyuluhan kepada masyarakat dan lain-lain.

\section{Kolam Retensi}

Kolam retensi adalah kolam atau waduk penampungan air hujan dalam jangka waktu tertentu. Fungsinya untuk memotong puncak banjir yang terjadi dalam badan air atau sungai (Dirjen Cipta Karya, 2012).

Berbeda dengan kolam detensi yang digunakan untuk menyimpan aliran sementara dalam waktu yang cukup untuk melakukan pengurangan air hujan dibagian downstream (hilir) atau aliran pipa ke elevasi yang dapat ditampung tanpa melebihi batas dari kapasitas hidrolik ( Lawrenceet al, 1996).

Menurut Desyi Astuti, dkk (2015), kolam retensi adalah suatu cekungan atau kolam yang dapat menampung atau meresapkan air di dalamnya. Kolam retensi dapat dibagi menjadi 2 (dua) macam yaitu :

1. Kolam Alami

Kolam alami adalah kolam retensi yang berbentuk cekungan yang sudah terbentuk secara alami dan dapat dimanfaatkan baik dalam kondisi aslinya maupun dilakukan penyesuaian.

2. Kolam Non Alami (Buatan)

Kolam non alami (buatan) adalah kolam retensi yang sengaja dibuat (dirancang) atau didesain dengan bentuk dan kapasitas tertentu pada lokasi yang telah direncanakan sebelumnya.

Menurut Desyi Astuti, dkk (2015), kolam retensi akan berfungsi dalam pengendalian limpasan permukaan dan konservasi air hujan dalam menjaga akumulasi air tanah. Dengan kata lain kolam retensi berfungsi untuk menyimpan dan menampung air sementara sebelum dialirkan ke sungai sehingga puncak banjir dapat dikurangi. Selain fungsi utamanya sebagai pengendalian banjir, manfaat lain dari kolam retendi adalah sebagai sarana air dan konservasi air.

Adapun terdapat tiga alternatif tipe kolam retensi yang sering digunakan di daerah dataran rendah (Dirjen Cipta Karya, 2012) : 
1. Kolam Retensi Tipe di Samping Badan Sungai

Kolam ini berada di samping badan sungai, dengan kelengkapan sistem :

- Kolam Retensi

- Pintu Inlet

- Bangunan Pelimpah Samping

- Pintu Outlet

- Jalan Akses Menuju Kolam Retensi

- Ambang Rendah di Depan Pintu Outlet

- Saringan Sampah

- Kolam Penangkap sedimen

Kesesuaian tipe kolam ini terhadap kondisi :

- Dipakai apabila tersedia lahan kolam retensi

- Kapasitas bisa optimal apabila lahan tersedia

- Tidak mengganggu sistem aliran yang ada

- Pemeliharaan lebih mudah

- Pelaksanaan lebih mudah

2. Kolam Retensi Tipe di Dalam Badan Sungai

Kolam retensi tipe dalam sungai yaitu kolam retensi dalam satu aliran badan sungai, dengan kelengkapan sistem :

- Kolam Retensi

- Tanggul Keliling

- Pintu Outlet

- Bendung

- Saringan Sampah

- Kolam Penangkap Sedimen

Kesesuaian tipe kolam retensi :

- Dipakai apabila lahan sulit didapat

- Kapasitas kolam retensi terbatas

- Mengganngu aliran yang ada di hulu

- Pelaksanaan lebih sulit

- Pemeliharaan lebih mahal

3. Kolam Retensi Tipe Storage Memanjang

Kelengkapan sistem kolam retensi :

- Saluran yang lebar dan dalam

- Cek dam/ bendung setempat

Kesesuaian tipe kolam retensi :

- Mengoptimalkan saluran drainase yang ada karena lahan tidak tersedia

- Kapasitas terbatas

- Mengganggu aliran yang ada

- Pelaksanaan lebih sulit
Parameter Statistik

Tabel .1 Parameter Statistik

\begin{tabular}{|c|c|c|}
\hline No. & Distribusi & Syarat \\
\hline \multirow{4}{*}{1.} & \multirow{4}{*}{ Normal } & $(x r a t \pm s)=68,27 \%$ \\
\hline & & $(x r a t \pm 2 s)=9,44 \%$ \\
\hline & & $\mathrm{Cs} \approx 0$ \\
\hline & & $\mathrm{Ck} \approx 3$ \\
\hline \multirow[b]{2}{*}{2.} & \multirow[b]{2}{*}{ Log Normal } & $\mathrm{Cs}=\mathrm{Cv} 3+3 \mathrm{Cv}$ \\
\hline & & $\begin{array}{l}\mathrm{Ck}=\mathrm{Cv} 8+6 \mathrm{Cv} 6+ \\
15 \mathrm{Cv} 4+\mathrm{Cv} 2+3\end{array}$ \\
\hline \multirow{2}{*}{3.} & \multirow{2}{*}{ Gumbel } & $\mathrm{Cs}=1,14$ \\
\hline & & $\mathrm{Ck}=5,4$ \\
\hline 4. & Log Person III & Selain Diatas \\
\hline
\end{tabular}

(Sumber : Hidrologi Terapan, Bambang

Triatmodjo, 2009)

Sedangkan persamaan untuk menentukan parameter statistik yang digunakan sebagai syarat adalah sebagai berikut :

- Menghitung Standar Deviasi (s)

$$
S=\sqrt{\frac{\sum\left(x_{i}-x\right)^{2}}{n-1}} .
$$

Keterangan :

$\mathrm{S}=$ Standar Deviasi

$\mathrm{Xi}=$ Nilai ke-i

$\mathrm{X}=$ Nilai Rata-rata Varian

$\mathrm{n} \quad=$ Jumlah Data

- $\quad$ Menghitung Koefisien Asimetri (Cs)

$C_{s}=\frac{\sum_{i=1}^{M}[\text { Xi } i \text {-Wrevata })^{3}}{\left[(n-1)(n-2)\left(s^{3}\right)\right.}$

Keterangan :

Cs = Koefisien Asimetri

$\mathrm{Xi}=$ Nilai ke- $\mathrm{i}$

$\mathrm{n} \quad=$ Jumlah Data

- $\quad$ Menghitung Koefisien Curtois (Ck)

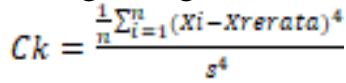

Keterangan :

$\mathrm{Ck}=$ Koefisien Curtois

$\mathrm{Xi} \quad=$ Nilai ke- $\mathrm{i}$

$\mathrm{n} \quad=$ Jumlah Data

$\mathrm{s} \quad=$ Standar Deviasi

- $\quad$ Menghitung Koefisien Variasi (Cv)

$C_{V}=\frac{s}{\text { Xrerata }}$.

Keterangan :

$\mathrm{Cv}=$ Koefisien Variasi

$\mathrm{s} \quad=$ Standar Deviasi

\section{Intensitas Curah Hujan}

Intensitas curah hujan adalah tinggi atau kedalaman air hujan per satuan waktu.Metode Mononobe digunakan sebagai metode perhitungan intensitas curah hujan, karena data curah hujan yang ada adalah data curah hujan 
harian (Joesron Loebis, 1992). Adapun persamaan yang digunakan seperti berikut :

$I=\frac{\mathbb{R}_{24}}{24}\left(\frac{24}{\mathrm{Te}}\right)^{\frac{2}{3}}$

Keterangan :

I = Intensitas Curah Hujan

$\mathrm{R}_{24}=$ Curah Hujan Maksimum dalam 24

jam

Tc $\quad=$ Waktu Konsentrasi (jam)

\section{Waktu Konsentrasi}

Rumus menentukan waktu konsentrasi menggunakan Metode Kirpich.Metode ini digunakan karena data yang diketahui adalah kemiringan lahan dan panjang lintasan aliran.

$T c=\left[\frac{0,97 \times L^{2}}{1000 \times 55}\right]^{0,385}$

Keterangan :

$$
\begin{array}{ll}
\text { Ts } & =\text { Waktu Konsentrasi (jam) } \\
\mathrm{L} & =\text { Panjang Lintasan }(\mathrm{km}) \\
\mathrm{S} & =\text { Kemiringan }
\end{array}
$$

\section{Debit Rencana}

Untuk perhitungan debit rencana akan menggunakan beberapa metode sebagai pembanding agar diperoleh debit banjir yang sesuai dengan keadaan DAS Batang Pangian. Metode-metode yang akan digunakan antara lain :

1. Metode Hasper

Metode Hasper digunakan pada luas DAS < $300 \mathrm{~km}^{2}$. Perhitungan debit banjir rencana untuk metode ini berdasarkan pada rumusrumus sebagai berikut:

$Q t=C \cdot \beta \cdot q \cdot A$

Dimana :

Koefisien run off (c)

$C=\frac{1+0,012 \cdot A^{0,70}}{1+0,075 \cdot A^{0,70}}$

Koefisien reduksi $(\beta)$

$\frac{1}{\beta}=1+\frac{t+3,70 \cdot 10^{-0,40 T}}{T c^{2}} \cdot \frac{A^{0,75}}{12}$

Waktu Konsentrasi (Tc)

$T c=0,10 \cdot L^{0,80} \cdot I^{-0,90}$

Hujan Maksimum (q)

$q=\frac{t \cdot R t}{3,6 \cdot t}$

Dimana :

Qt = Debit Banjir Rencana $\left(\mathrm{m}^{3} / \mathrm{dt}\right)$

Rt $=$ Hujan dengan periode ulang $\mathrm{T}$

tahun

$\mathrm{q}=$ Debit per satuan luas $\left(\mathrm{m}^{3} / \mathrm{dt} \cdot \mathrm{km}^{2}\right)$
2. Metode Melchior

Metode Melchior digunakan untuk luas DAS > $100 \mathrm{~km}^{2}$. Perhitungan debit banjir rencana metode ini mengyunakan rum (5) :

$Q t=C \cdot \beta \cdot q \cdot A$

Dimana :

$\beta=\frac{180+0,750 A}{150+A}$

$T=\frac{1000 \mathrm{~L}}{3600 \mathrm{~V}}$

$v=1,31 \sqrt[5]{\beta \cdot q \cdot A \cdot I^{2}}$

$C=0,52$

Keterangan :

Qt $\quad=$ Debit banjir rencana $\left(\mathrm{m}^{3} / \mathrm{dt}\right)$

$\mathrm{C}=$ Koefisien Limpasan

$\beta \cdots \cdots \cdot \cdots \cdot \cdots \cdot=\cdot$ Koefrisien pengurangan luas daerah

$\mathrm{q}=$ Intensitas maksimum hujan rata$\operatorname{rata}\left(\mathrm{m}^{3} / \mathrm{dt} / \mathrm{km}\right)$

$\mathrm{A}=$ Luas DAS $\left(\mathrm{km}^{2}\right)$

$\mathrm{T}=$ Waktu konsentrasi (jam)

$\mathrm{V}=$ Kecepatan aliran $(\mathrm{m} / \mathrm{dt})$

3. Metode Hidrograf Satuan Sintetik Nakayasu

HSS Nakayasu dikembangkan berdasarkan beberapa sungai di Jepang (Soemarto, 1987), bentuk HSS Nakayasu diberikasn oleh persamaan berikut :

$Q p=\frac{1}{9.6} \cdot \frac{A \cdot A 0}{0,9 T p+T 0.9}$.

Dimana :

$\mathrm{Tp}=\mathrm{Tg}+0,8 \times \mathrm{Tr}$

$\mathrm{Tg}=0,4+0,0058 \times \mathrm{L} \quad(\mathrm{L}>15$

$\mathrm{km})$

$\mathrm{TO}_{0,3}=\mathrm{C} \dddot{\mathrm{x}} \mathrm{Tg}$

$\mathrm{Tr} \quad=0,75 \mathrm{Tg}$

Keterangan :

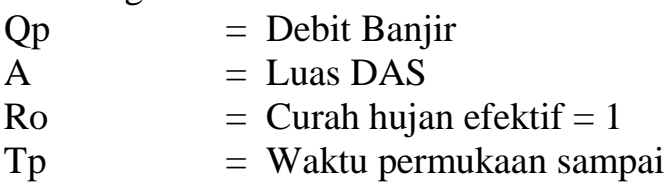
puncak hidrograf (jam)

$\mathrm{T}_{0,3} \quad=$ Waktu dari puncak banjir

sampai 0,3 kali debit puncak (jam)

$\mathrm{Tg}=$ Waktu Konsentrasi (jam)

$\operatorname{Tr}=$ Satuan waktu curah hujan

$\mathrm{C}=$ Koefisien karakteristik DAS

\section{METODE PENELITIAN}

Lokasi Penelitian

Lokasi penelitian berada di Nagari Gunung Selasih, Kecamatan Pulau Punjung, Kabupaten Dharmasraya, Provinsi Sumatera Barat.Daerah 
ini termasuk ke dalam bagian dari DAS Batang Pangian.

\section{Tahapan Penelitian}

Ada beberapa data yang dibutuhkan untuk melakukan penelitian ini, data yang dibutuhkan berupa :

- Data DEM (Digital Elevation Model)

Data DEM dapat di download di situs resmi penyedia data DEM secara gratis ataupun berbayar.

- Base Map DAS Batang Pangian

Base Map Daerah Aliran Sungai Batang Pangian bersumber dari ArcGIS Base Map.

- Data curah hujan maksimum

Data curah hujan didapatkan dari BWSS V (Badan wilayah Sungai Sumatra V) yang merupakan hasil pengukuran pada Stasiun PSDA Durian Simpai Silago.Data yang digunakan adalah data curah hujan selama sepuluh tahun bertutut-turut.

Setelah semua data yang dibutuhkan telah diperoleh, langkah selanjutnya adalah pengolahan data.Data-data yang diolah kemudian dilkukan analisis. Beberapa pengolahan data tersebut berupa :

- Penentuan daerah potensi banjir

Data DEM diolah menggunakan software ArcGIS 10.3 yang hasilnya berupa peta TWI (Topographic Wetness Index) yang berfungsi sebagai acuan penentuan daerah berpotensi banjir.

- Penentuan SubDAS

Data DEM diolah menggunakan ArcSWAT 10.3 untuk proses delineasi DAS yang menghasilkan SubDAS sebagai lokasi studi.

- Penentuan tata guna lahan

Tata guna lahan didapatkan dari digitasi

SubDAS yang mengacu pada Base Map.

Hasil tata guna lahan tersebut kemudian dihitung luasnya untuk mendapatkan koefisien limpasan yang akan digunakan untuk menghitung debit banjir.

- Perhitungan debit banjir

Debit Banjir dihitung dengan metoda rasional menggunakan data curah hujan selama sepuluh tahun berturut-turut.

- Perencanaan volume kolam retensi

Volume kolam retensi direncanakan dengan menggunakan nilai debit banjir serta waktu konsentrasi. Pada perencanaan kolam retensi diambil analisa nilai efektivitas kolam sebesar $75 \%$ agar kolam dapat berfungsi lebih baik.

\section{HASIL DAN PEMBAHASAN}

\section{Curah Hujan Maksimum}

Untuk mengetahui curah hujan maksimum, dibutuhkan data curah hujan tahunan dari Stasiun Pengukuran Curah Hujan.Data yang digunakan adalah data dari Stasiun Pengukuran Curah Hujan Durian Simpai Silago yang didapatkan dari BWSS V (Badan wilayah Sungai Sumatra V).

Tabel 2.Data Curah Hujan

Tahunan

\begin{tabular}{|c|c|c|}
\hline No. & Tahun & $\begin{array}{c}\text { Curah Hujan } \\
\text { Maksimum }\end{array}$ \\
\hline 1 & 2008 & 80 \\
\hline 2 & 2009 & 105 \\
\hline 3 & 2010 & 125 \\
\hline 4 & 2011 & 46 \\
\hline 5 & 2012 & 149 \\
\hline 6 & 2013 & 200 \\
\hline 7 & 2014 & 135 \\
\hline 8 & 2015 & 90 \\
\hline 9 & 2016 & 88 \\
\hline 10 & 2017 & 121 \\
\hline
\end{tabular}

Perhitungan Parameter Statistik

Tabel 3.Tabel Jenis Sebaran

\begin{tabular}{|c|c|c|c|c|}
\hline No. & Jenis Sebaran & Syarat & Hasil & Ket. \\
\hline \multirow{2}{*}{1} & \multirow{2}{*}{ Gumbel } & $\mathrm{Cs}=1,14$ & 0,554 & Tidak \\
\hline & & $\mathrm{Ck}=5,4$ & 2,427 & Tidak \\
\hline \multirow{4}{*}{2} & \multirow{4}{*}{ Log Normal } & $\mathrm{Cs}=3 \mathrm{Cv}+\mathrm{Cv}^{3}$ & & \\
\hline & & 1,174827788 & 0,554 & Tidak \\
\hline & & $\begin{array}{c}\mathrm{Ck}= \\
\mathrm{Cv}^{8}+6 \mathrm{Cv}^{6}+15 \mathrm{Cv}^{4}+\mathrm{Cv}^{2}+3\end{array}$ & & \\
\hline & & 3,45078409 & 2,427 & Tidak \\
\hline
\end{tabular}


Vol. 5 No.1 Januari 2022

http://jurnal.umsb.ac.id/index.php/RANGTEKNIKJOURNAL

\begin{tabular}{|c|c|c|c|c|}
\hline 3 & Log Person III & $(\mathrm{Cs} \neq 0)$ & $-0,671$ & Memenuhi \\
\hline
\end{tabular}

Tabel 4. Rekapitulasi Hasil Perhitungan Curah Hujan

\begin{tabular}{|c|c|c|c|c|}
\hline No. & Periode Ulang & Log Person III & Log Normal & Gumbel I \\
\hline 1 & 2 & 111,284 & 104,525 & 108,124 \\
\hline 2 & 5 & 150,275 & 141,174 & 158,988 \\
\hline 3 & 10 & 171,696 & 167,596 & 192,660 \\
\hline 4 & 25 & 194,654 & 203,393 & 235,217 \\
\hline 5 & 50 & 209,279 & 231,093 & 266,784 \\
\hline 6 & 100 & 222,122 & 260,924 & 298,118 \\
\hline
\end{tabular}

\section{Uji Keselarasan Sebaran}

Tabel 5Perhitungan Keselarasan Sebaran Chi-Square

\begin{tabular}{|c|c|c|c|c|c|c|c|c|}
\hline \multirow{2}{*}{ No. } & \multirow{2}{*}{\multicolumn{3}{|c|}{ Probabilitas \% }} & \multicolumn{4}{|c|}{ Jumla Data } & \multirow{2}{*}{$\mathrm{X}^{2}$} \\
\hline & & & & Oi & $\mathrm{Fi}$ & Oi_Fi & $(\mathrm{Oi}-\mathrm{Ei})^{2}$ & \\
\hline 1 & 20,33 & $<X<$ & 71,67 & 1 & 2,5 & $-1,5$ & 2,25 & 0,9 \\
\hline 2 & 71,67 & $<X<$ & 123,00 & 5 & 2,5 & 2,5 & 6,25 & 2,5 \\
\hline 3 & 123,00 & $<\mathrm{X}<$ & 174,33 & 3 & 2,5 & 0,5 & 0,25 & 0,1 \\
\hline 4 & 174,33 & $<\mathrm{X}<$ & 225,67 & 1 & 2,5 & $-1,5$ & 2,25 & 0,9 \\
\hline & & & & 10 & 10 & & & 4,4 \\
\hline
\end{tabular}

Karena $X^{2}$ pada perhitungan uji sebaran chi-square lebi kecil dari $\alpha 5 \%=5,991$, maka dicoba uji sebaran dengan metode lain.

Tabel 6Tabel Derajat Kebebasan

\begin{tabular}{|c|c|c|c|c|c|}
\hline $\begin{array}{c}\text { Derajat } \\
\text { Kebebasan } \\
(\mathrm{dk})\end{array}$ & \multicolumn{5}{|c|}{ Derajat nyata (level of significance, $\alpha$ ) } \\
\cline { 2 - 6 } & 0,2 & 0,1 & 0,05 & 0,01 & 0,001 \\
\hline 1 & 1,642 & 2,706 & 3,841 & 6,635 & 10,827 \\
\hline 2 & 3,219 & 4,605 & 5,991 & 9,21 & 13,815 \\
\hline 3 & 4,642 & 6,251 & 7,815 & 11,345 & 16,268 \\
\hline 4 & 5,989 & 7,779 & 9,488 & 13,277 & 18,465 \\
\hline
\end{tabular}

Tabel 7. Tabel Uji Sebaran Smirnov Kolmogorov

\begin{tabular}{|c|c|c|c|r|r|r|r|r|r|}
\hline No. & Tahun & $\mathrm{Xi}$ & $\mathrm{m}$ & $\mathrm{P}(\mathrm{X})$ & $\mathrm{P}(\mathrm{X}<)$ & $\mathrm{K}$ & $\mathrm{P}^{\prime}(\mathrm{X})$ & $\mathrm{P}^{\prime}(\mathrm{X}<)$ & $\mathrm{D}$ \\
\hline 1 & 2008 & 80 & 1 & 0,091 & 0,909 & $-0,79548$ & 0,111 & 0,889 & 0,020 \\
\hline 2 & 2009 & 105 & 2 & 0,182 & 0,818 & $-0,20884$ & 0,222 & 0,778 & 0,040 \\
\hline 3 & 2010 & 125 & 3 & 0,273 & 0,727 & 0,26047 & 0,333 & 0,667 & 0,061 \\
\hline
\end{tabular}


Vol. 5 No.1 Januari 2022

http://jurnal.umsb.ac.id/index.php/RANGTEKNIKJOURNAL

\begin{tabular}{l|c|c|c|c|c|c|c|c|c|c|}
\hline 4 & 2011 & 46 & 4 & 0,364 & 0,636 & $-1,59331$ & 0,444 & 0,556 & 0,081 \\
\hline 5 & 2012 & 149 & 5 & 0,455 & 0,545 & 0,82364 & 0,556 & 0,444 & 0,101 \\
\hline 6 & 2013 & 200 & 6 & 0,545 & 0,455 & 2,02038 & 0,667 & 0,333 & 0,121 \\
\hline 7 & 2014 & 135 & 7 & 0,636 & 0,364 & 0,49512 & 0,778 & 0,222 & 0,141 \\
\hline 8 & 2015 & 90 & 8 & 0,727 & 0,273 & $-0,56083$ & 0,889 & 0,111 & 0,162 \\
\hline 9 & 2016 & 88 & 9 & 0,818 & 0,182 & $-0,60776$ & 1,000 & 0,000 & 0,182 \\
\hline 10 & 2017 & 121 & 10 & 0,909 & 0,091 & 0,16661 & 1,111 & $-0,111$ & 0,202 \\
\hline
\end{tabular}

Analisa Intensitas Curah Hujan

Tabel 9Tabel Intensitas Curah Hujan

\begin{tabular}{|c|c|c|c|c|c|c|}
\hline \multirow{2}{*}{$\begin{array}{c}\mathrm{t} \\
\text { jam }\end{array}$} & \multicolumn{6}{|c|}{$\mathrm{R} 24$} \\
\cline { 2 - 7 } & $\mathrm{R} 2$ & $\mathrm{R} 5$ & $\mathrm{R} 10$ & $\mathrm{R} 25$ & $\mathrm{R} 50$ & $\mathrm{R} 100$ \\
\cline { 2 - 7 } & 111,28 & 150,28 & 171,70 & 194,65 & 209,28 & 222,12 \\
\hline 1 & 38,62 & 52,15 & 59,59 & 67,55 & 72,63 & 77,09 \\
\hline 2 & 24,32 & 32,85 & 37,53 & 42,55 & 45,74 & 48,55 \\
\hline 3 & 18,56 & 25,06 & 28,64 & 32,46 & 34,90 & 37,05 \\
\hline 4 & 15,32 & 20,69 & 23,64 & 26,80 & 28,81 & 30,58 \\
\hline 5 & 13,20 & 17,83 & 20,37 & 23,09 & 24,83 & 26,35 \\
\hline 6 & 11,69 & 15,79 & 18,04 & 20,45 & 21,98 & 23,33 \\
\hline 7 & 10,55 & 14,24 & 16,27 & 18,45 & 19,84 & 21,05 \\
\hline 8 & 9,65 & 13,03 & 14,89 & 16,88 & 18,14 & 19,26 \\
\hline 9 & 8,92 & 12,04 & 13,76 & 15,60 & 16,77 & 17,80 \\
\hline 10 & 8,31 & 11,23 & 12,83 & 14,54 & 15,64 & 16,60 \\
\hline 11 & 7,80 & 10,54 & 12,04 & 13,65 & 14,67 & 15,57 \\
\hline 12 & 7,36 & 9,94 & 11,36 & 12,88 & 13,85 & 14,69 \\
\hline 13 & 6,98 & 9,42 & 10,77 & 12,21 & 13,13 & 13,93 \\
\hline 14 & 6,64 & 8,97 & 10,25 & 11,62 & 12,49 & 13,26 \\
\hline 15 & 6,34 & 8,57 & 9,79 & 11,10 & 11,93 & 12,66 \\
\hline
\end{tabular}


Vol. 5 No.1 Januari 2022

http://jurnal.umsb.ac.id/index.php/RANGTEKNIKJOURNAL

\begin{tabular}{|c|c|c|c|c|c|c|}
16 & 6,08 & 8,21 & 9,38 & 10,63 & 11,43 & 12,13 \\
\hline 17 & 5,84 & 7,88 & 9,00 & 10,21 & 10,98 & 11,65 \\
\hline 18 & 5,62 & 7,59 & 8,67 & 9,83 & 10,56 & 11,21 \\
\hline 19 & 5,42 & 7,32 & 8,36 & 9,48 & 10,19 & 10,82 \\
\hline 20 & 5,24 & 7,07 & 8,08 & 9,16 & 9,85 & 10,45 \\
\hline 21 & 5,07 & 6,84 & 7,82 & 8,87 & 9,53 & 10,12 \\
\hline 22 & 4,91 & 6,64 & 7,58 & 8,60 & 9,24 & 9,81 \\
\hline 23 & 4,77 & 6,44 & 7,36 & 8,34 & 8,97 & 9,52 \\
\hline 24 & 4,64 & 6,26 & 7,15 & 8,11 & 8,72 & 9,26 \\
\hline
\end{tabular}

Hasil perhitungan intensitas curah hujan dalam kala ulang tertentu ini selanjutnya akan dimasukkan ke dalam grafik lengkung IDF (Intensity Duration Frequency). Grafik Lengkung IDF menggambarkan hubungan antara intensitas hujan dengan durasi hujan yang terjadi.Grafik IDF dari hasil perhitungan intensitas curah hujan dapat dilihat pada gambar (1).

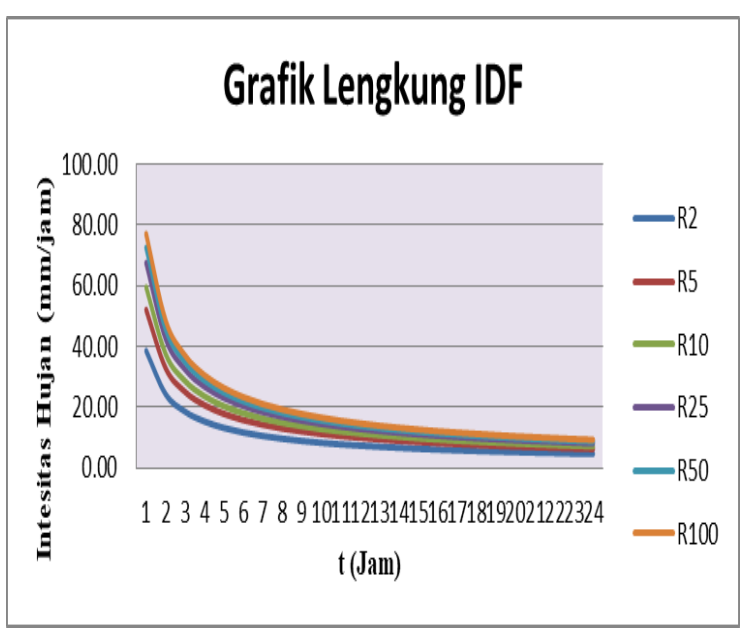

Gambar 1Grafik IDF Das Batang Pangian
Analisa Koefisien Limpasan

Tabel 10Nilai Koefisien Limpasan

\begin{tabular}{|l|c|}
\hline Penggunaan Lahan & Nilai C (\%) \\
\hline Hutan Tropis & $<3$ \\
\hline Hutan Produksi & 5 \\
\hline Semak Belukar & 15 \\
\hline Sawah & 40 \\
\hline Perkebunan & 70 \\
\hline Daerah Pemukiman & $70-90$ \\
\hline Bangunan Padat & 3 \\
\hline $\begin{array}{l}\text { Hutan Lahan Kering } \\
\text { Sekunder }\end{array}$ & 2 \\
\hline Hutan Primer & 5 \\
\hline $\begin{array}{l}\text { Hutan Tanaman } \\
\text { Industri }\end{array}$ & 20 \\
\hline Lahan Terbuka & \\
\hline
\end{tabular}

(Sumber : Suripin, 2002)

Tabel 11Nilai Koefisien Limpasan Komposit

\begin{tabular}{|c|l|r|r|r|r|}
\hline No. & \multicolumn{1}{|c|}{ Area (A) } & \multicolumn{1}{c|}{$\begin{array}{c}\text { Luasan } \\
\left(\mathrm{km}^{2}\right)\end{array}$} & $\mathrm{C}$ (Tabel) & \% Luas & C x \% Luas \\
\hline 1 & Sungai & 7,63 & 1 & 4,78 & 4,7768 \\
\hline 2 & Tanah Kosong & 4,72 & 0,2 & 2,95 & 0,5910 \\
\hline 3 & Sawah & 4,8 & 0,15 & 3,01 & 0,4508 \\
\hline 4 & Hutan & 125,45 & 0,02 & 78,54 & 1,5708 \\
\hline 5 & Pemukiman & 7,73 & 0,7 & 4,84 & 3,3876 \\
\hline
\end{tabular}




\begin{tabular}{|c|c|c|c|c|c|}
\hline 6 & Perkebunan & 9,4 & 0,4 & 5,88 & 2,3540 \\
\hline & Jumlah & 159,73 & & 100 & 13,1309 \\
\hline
\end{tabular}

Nilai koefisien limpasan yang didapatkan dari hasil perhitungan adalah 0,131 . Nilai ini akan digunakan sebagai faktor untuk perhitungan nilai debit banjir rencana pada tahap selanjutnya.

\section{Analisa Waktu Konsentrasi}

$S=$ Elevasi Atas-Elevasi Bawah

$S=\frac{978}{30 \mathrm{~km} \times 1000}$

Analisa Debit Banjir Rencana

Tabel 12Debit Banjir Metode Hasper

\begin{tabular}{|c|c|c|c|c|c|c|c|c|}
\hline $\mathrm{T}$ & $\mathrm{Rt}$ & $\mathrm{A}$ & $\mathrm{Tc}$ & $\mathrm{C}$ & $\beta$ & $\mathrm{R}$ & $\mathrm{q}$ & $\mathrm{Q}$ \\
\hline 2 & 111,284 & 159,73 & 8,204 & 0,392 & 0,728 & 99,193 & 3,359 & 153,284 \\
\hline 5 & 150,275 & 159,73 & 8,204 & 0,392 & 0,728 & 133,948 & 4,536 & 206,992 \\
\hline 10 & 171,696 & 159,73 & 8,204 & 0,392 & 0,728 & 153,041 & 5,182 & 236,497 \\
\hline 25 & 194,654 & 159,73 & 8,204 & 0,392 & 0,728 & 173,504 & 5,875 & 268,119 \\
\hline 50 & 209,279 & 159,73 & 8,204 & 0,392 & 0,728 & 186,540 & 6,316 & 288,264 \\
\hline 100 & 222,122 & 159,73 & 8,204 & 0,392 & 0,728 & 197,988 & 6,704 & 305,955 \\
\hline
\end{tabular}

Tabel 13Debit Banjir Metode Melchior

\begin{tabular}{|c|c|c|c|c|c|c|c|}
\hline $\mathrm{T}$ & $\beta$ & $\mathrm{R}$ & $\mathrm{q}$ coba & $\mathrm{v}$ & $\mathrm{Tc}$ & $\mathrm{q}$ & $\mathrm{Q}$ \\
\hline 2 & 0,9679 & 45,626 & 1,54 & 0,413249 & 20,17 & 1,5329 & 123,242 \\
\hline 5 & 0,9679 & 61,613 & 2,15 & 0,44177 & 18,86 & 2,2129 & 177,908 \\
\hline 10 & 0,9679 & 70,395 & 2,56 & 0,457463 & 18,22 & 2,6182 & 210,489 \\
\hline 25 & 0,9679 & 79,808 & 3,04 & 0,473459 & 17,60 & 3,0720 & 246,978 \\
\hline 50 & 0,9679 & 85,804 & 3,30 & 0,481294 & 17,31 & 3,3575 & 269,929 \\
\hline 100 & 0,9679 & 91,070 & 3,56 & 0,48865 & 17,05 & 3,6180 & 290,873 \\
\hline
\end{tabular}

Tabel 14Debit Banjir HSS Nakayasu

\begin{tabular}{|c|c|c|c|c|c|c|c|}
\hline \multirow{2}{*}{$\mathbf{t}$} & \multirow{2}{*}{$\mathbf{U}(\mathbf{t}, \mathbf{1})$} & \multicolumn{5}{|c|}{$\mathbf{Q}\left(\mathbf{m}^{\mathbf{3}} / \mathbf{d t}\right)$} \\
\cline { 3 - 7 } & & $\begin{array}{c}\mathbf{T r}= \\
\mathbf{2 t h}\end{array}$ & $\begin{array}{c}\mathbf{T r}= \\
\mathbf{5 t h}\end{array}$ & $\begin{array}{c}\mathbf{T r}= \\
\mathbf{1 0 t h}\end{array}$ & $\begin{array}{c}\mathbf{T r}= \\
\mathbf{2 0 t h}\end{array}$ & $\begin{array}{c}\mathbf{T r}= \\
\mathbf{5 0 t h}\end{array}$ & $\begin{array}{c}\mathbf{T r}= \\
\mathbf{1 0 0 t h}\end{array}$ \\
\hline$(\mathbf{j a m})$ & $\left(\mathbf{m}^{\mathbf{3}} / \mathbf{d e t} / \mathbf{m m}\right)$ & & & & & & 1,18 \\
\hline 0 & 0,00 & 1,18 & 1,18 & 1,18 & 1,18 & 1,18 & 8,18 \\
\hline 1 & 0,44 & 4,69 & 5,91 & 6,59 & 7,31 & 7,77 & 8 \\
\hline
\end{tabular}

Hasil pengukuran menunjukkan kemiringan titik terjauh DAS menuju kolam retensi sebesar 0,0036. Nilai kemiringan (S) akan digunakan sebagai faktor perhitungan waktu konsentrasi.

Setelah nilai (L) dan (S) sudah dihitung,

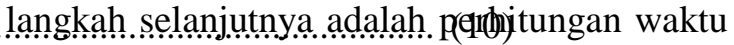
konsentrasi (Tc).Dari hasil perhitungan menggunakan metode Kirpiqh, didapatkan waktu konsentrasi sebesar 7,923 jam atau sekitar 475,38 menit. 
Vol. 5 No.1 Januari 2022

http://jurnal.umsb.ac.id/index.php/RANGTEKNIKJOURNAL

\begin{tabular}{|c|c|c|c|c|c|c|c|}
\hline 2 & 2,30 & 21,89 & 29,14 & 33,13 & 37,40 & 40,12 & 42,51 \\
\hline 3 & 6,09 & 63,47 & 85,30 & $\begin{array}{l}97,29 \\
\end{array}$ & 110,14 & 118,32 & 125,51 \\
\hline 4 & 7,11 & $\begin{array}{l}99,48 \\
\end{array}$ & 133,92 & 152,84 & 173,12 & 186,03 & 197,38 \\
\hline 5 & 5,37 & 112,43 & 151,40 & 172,82 & 195,77 & 210,39 & 223,23 \\
\hline 6 & 4,05 & 115,24 & 155,20 & 177,16 & 200,69 & 215,68 & 228,84 \\
\hline 7 & 3,06 & 112,07 & 150,92 & 172,26 & 195,14 & 209,71 & 222,51 \\
\hline 8 & 2,37 & 102,91 & 138,56 & 158,14 & 179,13 & 192,50 & 204,24 \\
\hline 9 & 1,97 & 85,84 & 115,50 & 131,79 & 149,26 & 160,39 & 170,16 \\
\hline 13 & 0,93 & 35,95 & 48,13 & 54,82 & 61,99 & 66,56 & 70,57 \\
\hline 14 & 0,77 & 30,00 & 40,10 & 45,65 & 51,59 & 55,38 & 58,71 \\
\hline 15 & 0,67 & 25,29 & 33,73 & 38,37 & 43,35 & 46,52 & 49,30 \\
\hline 16 & 0,58 & 21,51 & 28,64 & 32,55 & 36,75 & 39,42 & 41,77 \\
\hline 17 & 0,50 & 18,46 & 24,51 & 27,84 & 31,40 & 33,67 & 35,67 \\
\hline 18 & 0,44 & 15,97 & 21,15 & 24,00 & 27,05 & 28,99 & 30,70 \\
\hline 19 & 0,38 & 13,93 & 18,39 & 20,85 & 23,48 & 25,15 & 26,63 \\
\hline 20 & 0,33 & 12,25 & 16,12 & 18,25 & 20,54 & 21,99 & 23,27 \\
\hline 21 & 0,29 & 10,79 & 14,16 & 16,01 & 18,00 & 19,26 & 20,37 \\
\hline 22 & 0,25 & 9,53 & 12,46 & 14,07 & 15,79 & 16,89 & 17,85 \\
\hline 23 & 0,22 & 8,44 & 10,98 & 12,38 & 13,87 & 14,83 & 15,66 \\
\hline 24 & 0,19 & 7,48 & 9,69 & 10,91 & 12,21 & 13,04 & 13,76 \\
\hline \multicolumn{2}{|c|}{ MAX } & 115,24 & 155,20 & 177,16 & 200,69 & 215,68 & 228,84 \\
\hline
\end{tabular}

Tabel 15Rekapitulasi Debir Banjir Rencana

\begin{tabular}{|c|c|c|c|c|}
\hline \multirow{2}{*}{ No } & \multirow{2}{*}{$\mathrm{T}$} & \multicolumn{3}{|c|}{ Q (m3/dt) } \\
\cline { 3 - 5 } & & Hasper & Melchior & HSS Nakayasu \\
\hline 1 & 2 & 153,28 & 123,2418 & 115,24 \\
\hline 2 & 5 & 206,99 & 177,9085 & 155,20 \\
\hline 3 & 10 & 236,50 & 210,4891 & 177,16 \\
\hline 4 & 25 & 268,12 & 246,978 & 200,69 \\
\hline 5 & 50 & 288,26 & 269,9289 & 215,68 \\
\hline 6 & 100 & 305,95 & 290,8727 & 228,84 \\
\hline
\end{tabular}


Dari hasil perhitungan debit banjir rencana yang dipakai adalah debit banjir rencana HSS Nakayasu sebesar 200,69 m3/dt, karena debit yang didapat dipengaruhi oleh tata guna lahan pada DAS Batang Pangian.

\section{Perencanaan Kolam Retensi}

Untuk menghitung kapasitas kolam retensi yang dibutuhkan di daerah hilir Daerah Aliran Sungai Batang Pangian, digunakan persamaan yang membandingkan volume kolam retensi terhadap volume kumulatif debit banjir rencana saat waktu konsentrasi. $\quad$ n Kapsitas Kolam $=$ Luas Kolam $\times$ Kedalaman Kolam B

$=13000 \mathrm{~m}^{2} \times 2,74 \mathrm{~m}$

$=35620 \mathrm{~m}^{3}$

Setelah debit air maksimum yang masuk ke dalam Kolam Retensi diketahui, maka waktu yang dibutuhkan Kolam Retensi mampu menampung limpasan air hujan dapat dihitung sebagai berikut :

$$
\begin{aligned}
& \text { Waktu Limpasan }=\frac{\text { Kapasitas Kolam }}{\text { Qinflow }} . \\
& =\frac{35620 \mathrm{~m}^{\mathrm{a}}}{200,69 \mathrm{~m}^{\mathrm{3}} / \text { detik }} \\
& =2,96 \text { menit }
\end{aligned}
$$

$$
\begin{aligned}
& \text { Efektivitas }=\frac{\text { Volume Kolam Retensi }}{\text { Debit Puneak } \times \text { Waktu Ronsentrasi }} \times 100 \%
\end{aligned}
$$

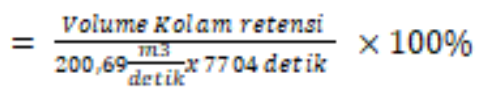

$$
\begin{aligned}
& =2,3 \%
\end{aligned}
$$

Dikarenakan efektifitas tampungan Kolam Retensi hanya 2,30\%<75\% maka Kolam Retensi yang direncanakan belum mampu manampung debit limpasan dengan maksimal. Agar Kolam Retensi dapat menampung debit yang melimpas secara baik maka debit banjir rencana harus dikurangi debit aliran pada DAS Batang Pangian. Debit aliran yang terjadi dapat dihitung dengan menggunakan rumus Manning

$Q=A \times V$

$A=(B+m \times h) \times h$

$V=\frac{1}{n} \times R^{\frac{2}{3}} \times I^{\frac{1}{2}}$

\section{m}

$$
\begin{aligned}
& R=\frac{A}{p} \ldots \ldots \ldots \ldots \ldots \ldots \ldots \ldots \\
& P=B+2 h \sqrt{m^{2}+1} .
\end{aligned}
$$

Dimana :

$$
\begin{aligned}
& \text { Q = Debit Banjir Rencana }\left(\mathrm{m}^{3 /} \mathrm{dt}\right) \\
& \mathrm{A} \quad=\text { Luas Penampang Basah }\left(\mathrm{m}^{2}\right) \\
& \mathrm{R}=\text { = Jari-jari Hidrolis }(\mathrm{m}) \\
& \mathrm{V}=\text { Kecepatan Aliran }(\mathrm{m} / \mathrm{dt}) \\
& \text { I }=\text { Kemiringan Dasar Saluran } \\
& \mathrm{P} \quad=\text { Keliling Penampang Basah } \\
& =\text { Angka Kekasaran Manning } \\
& \text { = Lebar Dasar Sungai }(\mathrm{m}) \\
& \text { =...Kemirinngann.Talod }
\end{aligned}
$$

Berdasarakan rumus-rumus di atas maka diperoleh nilai A sebesar $89,52 \mathrm{~m}^{2}$, nilai $\mathrm{R}$ sebesar 2,08 m, nilai $\mathrm{V}$ sebesar 2,17 m/detik, dan nilai $\mathrm{P}$ sebesar 42,92 m. Maka langkah selanjutnya yaitu menghitung debit aliran menggunakan persamaan (2.21).

$$
\begin{aligned}
& Q=89,52 \mathrm{~m}^{2} \times 2,17 \frac{\mathrm{m}}{d t} \\
& Q=194,63 \mathrm{~m}^{\mathrm{a}} / \text { detik }
\end{aligned}
$$

Debit limpasan yang diperoleh sebesar 200,69 $-194,63=6,05 \mathrm{~m}^{3} /$ detik. Selanjutnya hitung efektifitas Kolam Retensi dalam menampung debit limpasan yang ada dengan menggunakan rumus (2.20).

$$
\begin{aligned}
& \text { Efektifitas }=\frac{\text { Volume Kolam retensi }}{6,04 \frac{\text { mas }}{\text { drutik }} \times 7704 \text { detik }} \times 100 \% \\
& =\cdots 76 ; 44 \% \% \cdot 7.75 \% \\
& \text { Waktu Limpasan }=\frac{\text { Kapasitas Kolam }}{\text { Qinflow }} \\
& =\frac{35620 \mathrm{~m}^{\mathrm{a}}}{6,04 \mathrm{~m}^{\mathrm{a}} / \mathrm{detik}} \\
& =1,63 \mathrm{jam}
\end{aligned}
$$

Dari perhitungan diatas volume kolam retensi sebesar $35620 \mathrm{~m}^{3}$ di daerah sub DAS Batang Pangian untuk efektivitas sebesar $>75 \%$ dapat digunakan. Dengan waktu yang dibutuhkan selama 1,63 jam untuk kolam mencapai volume maksimum.

\section{PENUTUP}

Dari studi perencanaan kolam retensi berbasis...konservasi...Daeral(616Aliran Sungai Batang Air Dingin ini menghasilkan kesimpulan sebagai berikut.: (17) 
1. Dari hasil analisa aliran di ArcGIS, DAS Batang Pangian yang berada di Kabupaten Dharmasraya mengalami banjir akibat limpasan sungai dan berdampak pada pemukiman di daerah tersebut.

2. Pemilihan lokasi kolam retensi berdasarkan ketersediaan lahan dan diprioritaskan pada lokasi yang terdampak banjir menurut analisa Sistem Informasi Geografis dan keadaan di lapangan.

3. Dibutuhkan volume kolam retensi sebesar $35.620 \mathrm{~m}^{3}$ di daerah DAS Batang Pangian untuk efektivitas sebesar $>75 \%$ dengan waktu yang dibutuhkan selama 1,63 jam untuk mencapai volume maksimum.

4. Pada DAS Batang Pangian masih banyak ketersediaan lahan yang dapat digunakan dalam perencanaan kolam retensi, sehingga dapat dimanfaatkan untuk pengembangan kolam retensi di masa yang akan datang, apabila kapasitas satu kolam retensi tidak mencukupi.

\section{DAFTAR PUSTAKA}

Direktorat Pengairan dan Irigasi.(2008). Kebijakan Penanggulangan Banjir di Indonesia.1-17.

Dirjen Cipta Karya. (2012). Tata Cara Perencanaan Kolam Detensi, Kolam Retensi dan Sistem Polder. Diambil dari http://ciptakarya.pu.go.id/plp/upload/pera turan/buku_jilid_1_tata_cara_perencanaa n_drainase.pdf

Harto, S. (1993).Analisis Hidrologi (1 ed.). Jakarta: Gramedia Pustaka Utama.

Hasmar, H. (2011). Drainase Terapan. Yogyakarta: UII Press.

Junaidi, A., \& Nurhamidah. (2017). Flood problem in Padang city: The effectiveness solution. International Journal of Civil Engineering and Technology, 8(10), 1210-1219. Diambil dari

https://www.scopus.com/inward/record.u ri?eid=2-s2.0-

$85032507021 \&$ partnerID $=40 \& \mathrm{md} 5=777$

5078d0b941ecf8cb4e431c2fc1a3d

Lawrence, A. I., Marselek, J., Ellis, J. B., \& Urbonas, B. (1996).Stromwater detention \& BMPs. Journal of Hydraulic Research, 34(6), 799-813.

Loebis, J. (1992). Banjir Rencana untuk
Bangunan Air.Departemen Pekerjaan Umum, Jakarta.

Ministry of Agrarian and Spatial Planning.(2007). Indonesia Spatial Planning Act.

Nurhamidah, Junaidi, A., \& Anggraini, L. (2016).An immediate review of flood characteristics on delta lowland Sumatra using D8 model spatial analysis.

pelaGIS. (2011). Modul pelatihan sistem informasi geografis tingkat lanjut.

Presiden Republik Indonesia.(2012). PERATURAN PEMERINTAH REPUBLIK INDONESIA NOMOR 37 TAHUN 2012.5.

Sapardi, Y., Nurhamidah, \& Junaidi, A. (2018).Penentuan Potensi Daerah Banjir di Nagari Selayo dengan Spatial Hydrologic Model.Penentuan Potensi Daerah Banjir di Nagari Selayo dengan Spatial Hydrologic Model.

Somantri.(2008). Pemanfaatan Teknik Penginderaan Jauh untuk Mengindentifikasi Kerentanaan dan Risiko Banjir.8(2).

Sugiyanto, K. (2002). Penyebab Terjadinya Banjir. Penyebab Banjir.

Suripin.(2002). Sistem Drainase Perkotaan Yang Berkelanjutan. In Yogyakarta: Andi.

UNDP, T. T. N. (2007). Modul Pelatihan ArcGIS Dasar.

WWW.hariansinggalang.co.id.

(2018, Desember 7).Banjir di Dharmasraya, Sejumlah Jorong Terisolasi. Diambil dari (https://hariansinggalang.co.id/banjir-didharmasraya-sejumlah-jorongterisolasi/). 